\title{
SEMIÓTICA Y DERECHOS HUMANOS
}

Manuel Asdrúbal Prieto Salas*

\section{Aspectos generales de la semiótica}

Desde la creación de la semiótica como disciplina, por parte de John Locke, esta ha pasado a tomar un lugar relevante en los diferentes campos del conocimiento humano. Su evolución trasciende el metalenguaje de las matemáticas, logrando penetrar en el discurso de las Ciencias Sociales, entre las que se encuentran el Derecho y la Sociología. Esto ha sido posible gracias a los aportes de grandes pensadores, como Charles Sanders Pierce, Bertrand Russell, Rudolph Carnap y Charles William Morris, quienes lograron determinar que la semiótica precedía a las relaciones aritméticas básicas (Kalinowski \& Landowski, 1990).

Esta primera ola de semiólogos se enfocó en el desarrollo de dos de sus dimensiones más conocidas, la semántica y la sintáctica. Sin embargo, tiempo después, el filósofo Richard Montague comprendió que la relación más importante de los signos no está entre ellos mismos, ni tampoco con su significación, sino que estos necesitan de un intérprete, que tiene la función de organizar dichas dimensiones semióticas (Kalinowski \& Landowski, 1990). 
Gracias al aporte de Montague se lograron establecer las tres dimensiones básicas, o ramas de la semiótica general, que son: la sintáctica, que estudia la relación de unos signos con otros, o los sistemas de signos; la semántica, que estudia la relación de los signos con sus designaciones; y la pragmática, que estudia la relación de los signos con sus respectivos intérpretes (Gianella de Salama, 1986).

Ahora bien, de la operatividad de esta ciencia formal al lenguaje jurídico, surgen los siguientes interrogantes: ¿cómo se aplica la semiótica al Derecho? ¿Cómo opera la semiótica en los diferentes niveles normativo-jurídicos? Y, ¿es posible describir semióticamente los derechos humanos? La solución a todas estas inquietudes, especialmente a la tercera, es el objeto de esta investigación. En torno a las dos primeras preguntas existen grandes obras, entre las que está la del maestro Kalinowski. No obstante, respecto a la última pregunta formulada, la literatura existente se concentra exclusivamente en la dimensión semántica de los derechos humanos.

Inicialmente se debe distinguir entre los métodos de la filosofía del lenguaje científico y los de la filosofía del lenguaje jurídico. Las bases de la primera fueron diseñadas por los neopositivistas del Círculo de Viena, quienes sostenían que la utilidad de la filosofía debía restringirse al análisis lógico de las proposiciones que componen el lenguaje de una ciencia específica. Lo anterior, partiendo de proposiciones protocolarias que se adquieren de la experiencia sensible, para que de ellas se deriven otras secundarias, a través de las reglas de inferencia lógica (Kalinowski, 1973).

Bajo esta posición, la lógica y las matemáticas no son consideradas ciencias, ya que no están formadas por proposiciones protocolarias, siendo así reducidas a simples herramientas del saber humano. Pero las críticas formuladas por Karl Popper al método del positivismo lógico demostraron la imposibilidad de obtener proposiciones protocolarias por medio de la verificación empírica. De ese modo, la tradición de la verificación empírica es remplazada por la falsabilidad popperiana que, además, clarifica que la metafísica es importante para todo lenguaje bien formado (Mardones \& Ursúa, 2012).

Algunas de las consecuencias de la filosofía de Popper fueron el rescate de la lógica y la matemática como ciencias formales y la ampliación del campo de estudio de las filosofías científicas. Ejemplo de ello es que, en el mundo del Derecho, los objetos de estudio de la Filosofía del Derecho distan de ser análisis 
lógicos de las proposiciones jurídicas, sino que estos abarcan muchos más temas, como la Teoría de la Justicia, el concepto del Derecho desarrollado por filósofos y la Teoría de la Legitimidad de los Ordenamientos Jurídicos (Guastini, 2011).

De hecho, el desarrollo de la semiótica jurídica, así como de la lógica de los sistemas normativos, es objeto de estudio de la Teoría del Derecho producida por juristas (Guastini, 2011). Además, otro gran problema emergente en la aplicabilidad del modelo semiótico neopositivista al Derecho, es que este no diferencia entre el lenguaje de los juristas y el lenguaje del Derecho propiamente dicho (Kalinowski, 1973).

\section{La semiótica en el lenguaje del Derecho}

El lenguaje del Derecho es definido por Kalinowski (1973) como aquel donde el legislador enuncia-crea la regla jurídica, la cual compete al denominado enunciado jurídico. No obstante, en esta fase todavía no se habla de proposiciones jurídicas, ya que estas son la significación misma del enunciado (Echave, Urquijo $\&$ Guibourg, 2008). Precisamente, y a diferencia de otras ciencias que generan su propio léxico, de la identificación proposicional se evidencia que los términos usados en las normas jurídicas no son creados por el mismo Derecho. Estos son introducidos por el legislador con la significación propia de su lenguaje de origen.

A pesar de ello, existen términos que son inventados por el mismo Derecho a través de las denominadas normas determinativas, que se caracterizan por conceptualizar, mas no por ordenar (Von Wright, 1979). La búsqueda de significación a lo expresado en las reglas jurídicas lleva a que los intérpretes puedan deducir nuevas normas de dichos enunciados, para adaptarlos a nuevas realidades sociales (Kalinowski, 1973).

Además de las definiciones explícitas determinativas, existen también expresiones implícitas del "deber ser", como la permisión, la obligación, la prohibición y la facultad (Von Wright, 1951). En la mayoría de los eventos, estas no se encuentran en la sintaxis de las reglas, sino que es función del intérprete lograr deducirlas. Por ejemplo, cuando la regla establece: "El que matare a otro incurrirá en una pena privativa de la libertad de 10-47 años", existe una obligación implícita dirigida a un sujeto normativo específico, que en este caso es el juez penal, 
toda vez que solo él posee la obligación de hacer efectiva la pena al corroborar los hechos (Prieto, 2015).

No solo las expresiones implícitas afectan a los intérpretes del Derecho, ocurre lo mismo con las explícitas, lo que lleva a que cada vez que determinado agente esté en frente de una expresión creada por una norma determinativa, deberá usarla con esa significación artificial en todos los casos relevantes para el sistema jurídico (Kalinowski, 1973).

Ahora bien, teniendo claridad sobre las expresiones que hacen parte del lenguaje del Derecho, es posible identificar su funcionamiento desde las distintas dimensiones del proceso semiótico, como la pragmática, la semántica y la sintáctica. En primer lugar, la dimensión pragmática del Derecho es definida como la relación de sus expresiones con los sujetos que las enuncian (Kalinowski, 1973), en otras palabras, se centra en la relación del legislador con sus enunciados. Sin embargo, esta definición puede simplificar y omitir detalles importantes de la comunicación básica. Lo anterior, puesto que los intérpretes no necesariamente tienen que ocupar la posición de los emisores en la relación comunicativa, de hecho, también pueden ocupar la de los receptores. En la Teoría Jurídica, estos últimos son denominados como sujetos normativos (Von Wright, 2001).

Incluso la versión simplista de la pragmática jurídica no es tan clara, porque la posición del legislador como fuente única del Derecho es obsoleta, teniendo en cuenta que en la actualidad existen diversas fuentes distintas de la ley y cada una de ellas cuenta con su propio emisor. Por su parte, Kalinowski (1973) sostiene que hay tantos emisores como corrientes de pensamiento jurídico, debido a que el legislador, para un iusnaturalista, no puede ser el mismo que para un iuspositivista. En conclusión, se puede sostener que la pragmática del lenguaje del Derecho estudia la relación de las expresiones jurídicas, ya sea con sus emisores o con sus destinatarios.

En segundo lugar, la semántica del Derecho se enfoca en la distinción entre el enunciado normativo y su respectivo significado -también llamado proposición normativa-. Hay que tener en cuenta que estos no son términos sinónimos, puesto que los enunciados normativo-jurídicos se refieren a las oraciones emitidas por los legisladores en ejercicio de sus funciones, y estos, como toda oración, significan algo. Precisamente su significado es lo que se conoce como proposición (Echave, Urquijo \& Guibourg, 2008). 
Pero en el campo del Derecho existe una dificultad adicional a la de la semiótica tradicional, que se refiere a la falta de técnica legislativa en la redacción de reglas jurídicas. La ausencia de racionalidad en esta técnica, desemboca en una trabajo interpretativo desgastante, que en muchas ocasiones lleva a designaciones innecesarias de los enunciados normativos (Campos, 2006). Por otra parte, cuando se reúnen los requisitos mínimos de racionalidad, esto no implica que la labor identificativa de significación sea menos exigente. Como se relacionó anteriormente, la mayoría de enunciados normativos no formulan su carácter deóntico expresamente o, en otras palabras, la proposición jurídica, por lo que la mayor parte de la labor hermenéutica de los intérpretes del Derecho consiste en descifrarla (Kalinowski, 1995).

En tercer lugar, las teorías tradicionales de la sintaxis jurídica son bastante equívocas respecto a su descripción funcional. Esto se debe a que sostienen que las formulaciones que no poseen la sintaxis de norma, no pueden ser consideradas reglas jurídicas genuinas. La afirmación es problemática, por lo que se ha mencionado a lo largo de este apartado, y es que la mayoría de los enunciados normativos, en los ordenamientos jurídicos actuales, omiten usar el lenguaje prescriptivo para la redacción de reglas. Sin embargo, esto no significa que no pertenezcan al Derecho, razón por la que la juridicidad de una regla no se puede determinar de acuerdo a su manejo de una sintaxis adecuada. A pesar de ello, los problemas interpretativos de identificación proposicional deben ser resueltos a través de una técnica legislativa racional, so pena de que dicho enunciado sea incomprensible y a la vez insatisfactible (Campos, 2006).

\section{La semiótica en el lenguaje de los juristas}

Por otra parte, Kalinowski (1973) resalta un nuevo tipo de lenguaje que está presente en la semiótica jurídica, el llamado lenguaje de los juristas. Este se caracteriza por ser de una riqueza gramatical más amplia que el del Derecho. El de los juristas funciona como un metalenguaje, desarrollado sobre la proposición normativa, siendo en muchos casos descriptivo y no prescriptivo, porque sus formulaciones se hacen a nivel teórico o dogmático.

Algunos semiólogos del Derecho, incluyendo a Von Wright, Landowski y Kalinowski, sostienen erróneamente que el lenguaje de los jueces como juristas 
no produce una norma genuina. No obstante, las formalizaciones de estos grandes pensadores no toman en cuenta, por cuestiones históricas, el fenómeno de la constitucionalización del Derecho, el cual amplía el poder prescriptivo de las sentencias de esta índole, afectando no solo a las partes, sino también sus motivaciones, que deben ser atendidas por el conglomerado social. Además, en los sistemas constitucionalizados, las altas cortes asumen la posición de legislador negativo (Prieto, 2016).

A pesar de todo, dicha propuesta es superior a la de autores como Cruz Parcero, quien sostiene que los juristas son todos los habitantes del mundo (Courtis, 2006), ignorando que una cosa es actuar como sujeto normativo y otra muy distinta es desarrollar un metalenguaje del Derecho, en otras palabras, no es lo mismo obedecer que describir las causas y efectos de la obediencia.

\section{La semiótica de las expresiones normativas llamadas derechos humanos}

Lastimosamente, las teorías formalizadoras desarrolladas a mediados del siglo Xx solo pueden dar cuenta de las expresiones jurídicas más básicas, o sea, de las llamadas reglas, conllevando una serie de limitaciones respecto a algunos fenómenos jurídicos, entre los cuales se encuentran las expresiones normativas llamadas principios. La posibilidad de formalizar este último tipo de entidad normativa es indispensable para trabajar la semiótica de los derechos humanos, toda vez que sintácticamente se corresponden.

Los usos emotivos de este tipo de expresiones, aunados a las percepciones disímiles que tienen las diversas corrientes del pensamiento jurídico, dificultan la elaboración de un concepto unívoco sobre los derechos humanos. Sin embargo, el jurista Gregorio Peces-Barba (1995) ha logrado decantar varias descripciones, que no son acordes con el funcionamiento de los ordenamientos jurídicos actuales.

Las críticas de Peces-Barba van enfocadas a los problemas lingüísticos que subyacen al definir los derechos humanos como un producto del derecho natural, como un tipo de derechos públicos subjetivos, como formas de libertades públicas y como rama de la moral convencional. Según él, todas estas corrientes jurídicas no son objetivas en los diseños semánticos de los signos jurídicos, sino que tienen fuertes vínculos con cuestiones culturales, explicaciones históricas e 
ideológicas, etc., factores que imposibilitan la formulación de un concepto universal y objetivo de los derechos humanos (Peces-Barba, 1995).

Tradicionalmente, los derechos humanos poseen dos nociones comunes, ampliamente reconocidas, que, desde una perspectiva lingüística, no son de utilidad en la construcción de un concepto inequívoco. La primera de estas nociones afirma que los derechos humanos son la materialización de una pretensión moral fuerte que busca dignificar al hombre. Bajo esta postura, dichos derechos sobrepasan los ordenamientos jurídicos locales, al punto de que aunque estos no hayan sido reconocidos en ninguna codificación, todos los ciudadanos de un Estado tienen la facultad para ejercerlos sin coacción alguna. Incluso, si existiese alguna prohibición para su ejercicio, esta no representaría ningún impedimento por su carácter supranacional.

La segunda noción afirma que los llamados derechos humanos ya están reconocidos en el acápite de los derechos fundamentales, consignados en las constituciones nacionales de los Estados contemporáneos occidentalizados. De igual manera, están debidamente protegidos por garantías constitucionales, como la acción de amparo (España) o la acción de tutela (Colombia) (Peces-Barba, 1995).

Un análisis detallado de estas dos posiciones tradicionales revela que ambas son incompatibles entre sí, ya que han sido diseñadas por teorías del Derecho disímiles. En cuanto a la primera noción, el modelo que se evidencia es un iusnaturalismo racional, caracterizado principalmente por considerar que existen derechos que son inherentes o innatos a la naturaleza humana. Por ende, para este modelo todos los conjuntos normativos que conforman el corpus del Derecho son simples teoremas, que se desprenden de los axiomas naturales llamados principios universales del hombre (Kant, 2002).

Por otra parte, la segunda noción tradicional corresponde a una postura iuspositivista, que considera que el Derecho no existe si no está previamente axiomatizado en una norma jurídica. Esto conlleva la regionalización del Derecho, dejando en tela de juicio su calificativo humano, que no es una muletilla, sino que posee la pretensión de ser adjudicado y garantizado para toda la especie y no solo para un grupo social determinado (Nino, 2001). El hecho de que exista incompatibilidad conceptual sobre un mismo término, refleja un grave problema de identidad lógica. 


\section{Problemas lingüísticos en las expresiones llamadas derechos humanos}

El ejercicio depurativo del concepto derecho humano, para que logre satisfacer mínimamente el criterio de identidad lógica, requiere de la exposición de los problemas que padecen sus distintas versiones, las cuales responden únicamente a una visión sesgada del Derecho, dejando de lado su importancia lingüístico-semántica.

La primera crítica se hace a la visión iusnaturalista de los derechos humanos, ya que ella representa una noción racionalista, que prescinde de los componentes históricos de la realidad social mundial, que dan a conocer estas expresiones jurídicas a la comunidad internacional (Peces-Barba, 1995). Es decir, pensar que su origen es de naturaleza racional implica, ineludiblemente, que cualquier individuo, en cualquier sociedad, ha pensado en ellos independientemente de su situación personal o social, más o menos como sucede con la aritmética, en donde el producto de dos más dos es igual a cuatro, sin importar en qué lugar del globo se esté situado.

Esta postura "racionalista" es fuertemente criticada por Riccardo Guastini (2011), quien desarrolla la tesis débil y debilísima del Derecho, para mostrar la importancia de los sucesos históricos en la construcción e interpretación de los ordenamientos jurídicos. A pesar de las serias críticas que han logrado develar las limitaciones de la descripción naturalista, no se debe ignorar que esta teoría del Derecho ayuda al nacimiento de los grandes axiomas de los derechos humanos. Tómese como ejemplo el concepto de dignidad humana medieval, que junto a su respectiva bifurcación en el principio universal de la igualdad y el principio universal del libre albedrio, es propuesta por el famoso teólogo y filósofo Giovanni Pico Della Mirandola (2004), en una obra naturalista de corte teológico.

Otra perspectiva inadecuada, es la referente a los derechos públicos subjetivos como la versión positivista de los derechos humanos. Esta es desarrollada por la Escuela de Derecho Público Alemán del siglo XIX y se caracteriza principalmente por su riqueza lógica y lingüística. Irónicamente, dichas fortalezas representan uno de sus principales obstáculos para que esta sea considerada el paradigma de los derechos humanos. Lo anterior se debe a que su diseño lingüístico está dirigido a un público académico especializado, siendo inaccesible para los que no están relacionados con los tecnicismos jurídicos. Por ello, a través de 
este modelo se omite la condición de acceso "universal" que debe caracterizar a este tipo de expresiones jurídicas (Peces-Barba, 1995).

Además, estos derechos dependen, en gran medida, de la teoría del estatus, que aborda situaciones creadas por el Derecho Objetivo, de las cuales se desprenden los derechos públicos subjetivos. Esta dependencia genera grandes inconvenientes para que sean considerados el prototipo de los derechos humanos, toda vez que la historia misma ha señalado las nefastas consecuencias que surgen de la eliminación del estatus jurídico de la persona (Peces-Barba, 1995). Otro inconveniente que presenta este modelo, es que los derechos públicos subjetivos son limitaciones al ejercicio del poder público, o sea, solo opera contra las entidades estatales, mas no contra particulares. Este último factor no puede ser omitido, ya que es medular para la construcción de una teoría plausible de los derechos humanos (Peces-Barba, 1995).

El otro gran modelo positivista se gesta en Francia, bajo el nombre de libertades públicas. Al igual que la versión alemana, esta es diseñada para positivizar garantías jurídicas que hagan esgrimible el Derecho en contra del Estado, pero, a diferencia de los derechos públicos subjetivos, el lenguaje empleado por los franceses no es tan técnico, lo que permite una mayor difusión (Peces-Barba, 1995).

Además de las versiones naturalistas y positivistas de los derechos humanos, existe en la actualidad el modelo iusmoralista, creado por el jurista norteamericano Ronald Dworkin. Siguiendo las bases rawlsianas, consignadas en la teoría de la justicia, existen unos acuerdos de justicia individuales que, por medio del llamado velo de la ignorancia, permiten la construcción de principios de justicia intersubjetivos (Rawls, 1993). Dworkin considera que, en la fase inicial, lo que conviene no son conceptos de justicia propiamente dichos, sino posiciones morales individuales, las cuales, a la postre y por medio del acuerdo, construyen una moral convencional de la que se desprenderá el derecho (Dworkin, 2007).

Gran parte del desarrollo teórico del iusmoralismo está en la determinación de una posición moral válida, ya que no todas las posiciones individuales pueden ser calificadas de correctas, lo que impide poder presentarlas al debate público político. La "verificación" de la validez moral tiene que satisfacer unos criterios básicos de racionalidad, entre los cuales están: 
1. La posición moral no puede basarse en argumentos prejuiciosos, ya que los prejuicios son posturas fundadas en consideraciones superadas por la humanidad;

2. Los odios derivados de la posición moral no pueden estar justificados en aspectos emocionales o fobias;

3. La posición moral no puede estar anclada a situaciones de hecho falsas, o que no admitan verificación empírica;

4. Por último, la posición moral no debe ser una copia injustificada de la posición moral de otro individuo (Prieto, 2015).

Para que la posición individual sea válida, estos cuatro criterios de racionalidad deben ser satisfechos en su totalidad. Sin embargo, según Dworkin, existe una excepción para los criterios tres y cuatro, que se da cuando la posición moral que se copia de otro sujeto proviene de la religión. En dicho evento, el argumento individual puede llegar a ser válido, pero no podrá transgredir los puntos uno y dos (Prieto, 2015).

El cumplimiento de los cuatro criterios de racionalidad desarrolla el campo de la responsabilidad ética del individuo. En esta, los sujetos tienen la obligación de hacer de su vida "algo valioso", para lograr satisfacer el objetivo universal de "la buena vida". De la originalidad ética emana la moral individual, siendo fundamental para la creación de esta última (Dworkin, 2014). A través del debate público, una moral subjetiva bien fundamentada posibilita la construcción de la moral convencional, así como la moral política genera una serie de subsistemas dentro los que está el Derecho. Dworkin denomina a este proceso generativo del sistema jurídico como la estructura del árbol (Dworkin, 2014).

A pesar de la intención de Dworkin de separarse teóricamente de las corrientes tradicionales del pensamiento jurídico, al inventar el iusmoralismo, el autor recae en algunas de ellas, ya sea en su etapa formativa o en su etapa operativa. Respecto a su origen, al afirmar que los derechos humanos son previos a toda formación jurídica o estatal, afianza una semejanza con las posturas naturalistas de corte racional y teológico. También hay un gran factor conflictivo a nivel lingüístico, debido a que muchas veces las traducciones que se hacen de las obras anglosajonas llevan a equívocos. Por ejemplo, para los anglosajones los términos "law" y "right" son prácticamente independientes entre sí, en cambio, en América 
Latina, así como en Europa Continental, dichos términos son usados sin mucha distinción (Peces-Barba, 1995). Es decir, existen problemas en la correspondencia de la referencia semántica. El conflicto operativo surge al carecer de garantías jurídicas que permitan su exigencia.

Aunque desde la ética del individuo parezca plausible el proceso formativo del derecho, se observa una clara división entre esta Teoría jurídica, las tradiciones históricas y culturales de cada nación y los avances tecnológicos. Dworkin (2014) sostiene, en Justicia para erizos, que existen modos de volver objetiva la moralidad, desde una teoría de la verdad insuficiente e incorrecta, que desconoce miles de años de evolución conceptual y que, además, establece valores jurídicos objetivos. Lastimosamente, a pesar de ser una teoría formalmente atractiva, su enfoque es estrictamente sustancial, revelándose su dificultad para lograr adaptarse a otros componentes de realidad humana, distintos a la ética y a la moral, como es el caso de la tecnología. Desde la perspectiva del jurista norteamericano, sería extremadamente complejo hablar de la posibilidad del derecho humano al internet (Peces-Barba, 1995).

La expresión "derecho moral" no puede tomarse emotivamente como algo bueno para todo ordenamiento jurídico, puesto que un análisis detallado revela sus grandes conflictos operativos, al sostener que por medio de los derechos morales se evitan los problemas típicos del positivismo ideológico. Si estos derechos son previos al Estado y al ordenamiento jurídico, entonces son creados, generalmente, a través de la convención social. Si se establece la inviolabilidad de dichas expresiones, incluso haciéndolas contramayoritarias, ¿no surge la posibilidad de que estos derechos iniciales sean la expresión de deseos egoístas? En cuanto a la pregunta, vale recordar la protección jurídica especial de la que goza la propiedad privada en las sociedades liberales, ya que en estas, la mayoría de los miembros carecen de acceso a este derecho por cuestiones fácticas mas no jurídicas (Habermas, 2001).

\section{La semántica de los derechos humanos}

Identificados los límites conceptuales que ofrecen las nociones de derechos naturales, derechos públicos subjetivos, libertades públicas y derechos morales, cabe 
preguntarse ¿cuál será el modelo jurídico que se adapta mejor al concepto de derechos humanos?

Para empezar, los derechos humanos no pueden ser entendidos como un producto de la moral, pero es evidente que estas expresiones jurídicas aluden a un derecho moralizado (Peces-Barba, 1995). Este hecho abre la posibilidad, como lo expresan Luigi Ferrajoli y Gregorio Peces-Barba, de que sean diseñados lingüísticamente por medio del modelo de los derechos fundamentales.

La plausibilidad de los derechos fundamentales como el paradigma de los derechos humanos radica en que este tipo de expresiones jurídicas poseen una dimensión moral y jurídica formal básica. Estas dos dimensiones son necesarias para la axiomatización de la dignidad humana y su correspondiente operatividad, toda vez que, sin su forma positiva, el derecho carecería de elementos coactivos para garantizar su satisfacción (Peces-Barba, 1995). Además, la flexibilidad de la noción "derechos fundamentales", permite su adecuación a los tres rasgos conceptuales de los derechos humanos, que son: exigencias éticas justificadas; exigencias éticas especialmente importantes; y garantías de protección jurídica a dichas exigencias.

La justificación e importancia de las exigencias éticas son el primer nivel de una moral convencionalizada. Lograr dichas calificaciones requiere que los productos del acuerdo social se deriven del concepto de dignidad humana. En todo caso, no es suficiente que se logre un simple acuerdo moral, pues este último necesita ser asimilado por el derecho positivo, con el propósito de hacer efectivo el contenido de dichas pretensiones morales (Peces-Barba, 1995). Es decir, se necesita obligatoriamente pasar de una postura naturalista a una forma positiva, a través del proceso de axiomatización. En este sentido, los criterios de valuación de pertenencia al conjunto son los argumentos que justifican la importancia del criterio moral como derivado de la dignidad (Prieto, 2015).

Como se puede observar, este nuevo esquema va más allá de las teorías tradicionales del Derecho, que no logran satisfacer en ningún caso la complejidad estructural de un derecho humano. El problema de las posturas iusnaturalistas e iusmoralistas, es que rechazan vehementemente el Derecho Positivo, incluso el mismo Dworkin se denominaba anti-positivista. Sin embargo, sin una forma axiomatizada dentro de un ordenamiento jurídico, estas expresiones no serían derechos, sino simples críticas morales. El problema del positivismo jurídico radica 
en el rechazo de la moral como parte del concepto del derecho y, al referirse exclusivamente a esto, deja de lado el fundamento de las cuestiones conceptuales (Peces-Barba, 1995).

La formulación lingüística de los derechos humanos requiere de una teoría integral, que pueda dar cuenta de sus aspectos conceptuales y fundamentales. En otros términos, debe responder adecuadamente el "para qué" y el "por qué" de este tipo de expresiones jurídicas. Operativamente, la conexión entre estas dos nociones se hace a través del "poder", el cual es representado por el Estado, transformado, a partir de la modernidad, en el punto de referencia jurídica (PecesBarba, 1995). Sin el apoyo del Estado, los valores no se convertirían en derechos, ya que estos carecerían de fuerza coactiva, en otras palabras, no podrían exigirse ni tampoco satisfacerse.

La necesidad del poder estatal como agente integrador demuestra otro fallo en la perspectiva de los derechos morales, ya que estos serían inoperantes en la práctica jurídica, toda vez que, si no llegasen a ser positivizados en una constitución política, se transformarían en simples críticas morales carentes de garantías de exigibilidad (Peces-Barba, 1995). La sincretización de estas dos posturas se conoce como la Teoría Dualista de los Derechos Humanos, la cual, a pesar de su riqueza explicativa, tiene falencias por la ausencia de propiedades definitorias.

El éxito de la aproximación lingüística requiere de la introducción de más propiedades, que puedan dar cuenta del fenómeno jurídico en la realidad. Para tal fin, Peces-Barba (1995) sostiene la necesidad de incluir la eficacia jurídica como un tercer elemento de la perspectiva dualista de los derechos humanos. La importancia de esta noción radica en su función conceptual, ya que se circunscribe en la descripción de aspectos sensibles de la operatividad normativa, en otras palabras, es el factor empírico de toda norma (Kelsen, 1986).

Usualmente, en los ordenamientos jurídicos de corte europeo-continental, la eficacia no es vista como un elemento indispensable de validez. O sea, las normas solo necesitan cumplir con los requerimientos de promulgación, establecidos en la Constitución, para existir en el mundo del Derecho. Pero hay expresiones jurídicas, como los derechos humanos, que requieren de la eficacia para validarse en el tiempo (Kelsen, 1986). Esta propiedad relaciona coherentemente el contenido del derecho con su entorno social-empírico, ya que no tendría sentido positivar un derecho con el rango de fundamental, si este es imposible de lograr en el mundo real. 
De hecho, la insuficiencia de este elemento ha generado una serie de controversias en torno a la consideración de la "propiedad privada" como un derecho fundamental, puesto que, en el mundo sensual, esta se encuentra restringida por cuestiones fácticas mas no de Derecho (Peces-Barba, 1995). Por ejemplo, aunque todos los habitantes de la tierra posean el derecho de ser propietarios (mundo contrafáctico del Derecho), solo un pequeño grupo de individuos logra alcanzarlo, gracias a sus recursos financieros.

Otra postura plausible, sobre la aproximación lingüística al concepto de derechos fundamentales, es la Teoría Formal-estructuralista del jurista italiano Luigi Ferrajoli. Para él, los derechos fundamentales "son derechos subjetivos que corresponden universalmente a todos los seres humanos dotados con el estatus de persona, ciudadano, o persona con capacidad de obrar" (Ferrajoli, 2009, p. 19). En este punto subyace una problemática, vinculada a la adición del componente lógico cuantificador de la universalidad, ya que la existencia de Estados donde el valor supremo de la dignidad humana está limitado por cuestiones políticas, rompe con la propiedad de adjudicación universal.

La mayoría de los derechos fundamentales están contenidos en las cartas políticas de países de corte occidental, pero debe entenderse que no todos estos derechos deben estar consignados en una Constitución, sino que existen también otras formas jurídicas, como el bloque de constitucionalidad y el derecho procesal. Por una parte, el bloque de constitucionalidad alude a todas las normas que no están consignadas en una Constitución, pero que, debido a su contenido, tienen un tratamiento similar a los derechos fundamentales (Vergara, 2000). Por otra parte, el derecho procesal, desde la postura formalista-estructuralista, es considerado como fundamental, por ser de uso universal; aunque dependa de la materia sustancial que pretende garantizar, sigue siendo un derecho que está en cabeza de "todos" (Ferrajoli, 2009).

Es evidente que, desde la postura formalista, el elemento de fundamentación de la teoría tríadica queda de lado, dejando como propiedad configuradora del derecho humano fundamental su capacidad de "adjudicación universal", es decir, el hecho de recaer en los hombres sin atender a su contenido (Ferrajoli, 2009). Lo dicho anteriormente muestra uno de los puntos débiles de la descripción formalista, ya que al dejar de lado su relación con la ética y la moral, el derecho pierde su 
justificación interna y externa, permitiendo que cualquier cosa ajena a la dignidad humana pueda llenar su contenido, perdiendo universalidad, pero por sustancia.

A pesar de los inconvenientes sustanciales, Ferrajoli (2009) sostiene que su visión formalista es útil y ventajosa, ya que permite a cualquier sociedad política desarrollar modelos de derecho distintos a los usados en los países occidentalizados. En otras palabras, fomenta un entendimiento diverso de los elementos sustanciales del derecho. Por ejemplo, en una sociedad totalitaria comunista, los derechos fundamentales son distintos a los que se enuncian en una sociedad liberal (Ferrajoli, 2009). En este punto surge una cuestión conflictiva respecto a la universalidad de los derechos humanos como derechos fundamentales, y es que ambos no pueden ser los mismos en todas las sociedades humanas.

Esto lleva a la cuestión de si es posible, en un mundo tan diverso, satisfacer una visión universal de los derechos. "Universal” alude aquí, según el contexto ferrajoliano, a su sentido lógico, es decir, a los cuantificadores como constantes del lenguaje proposicional sobre la mayor extensión de los términos. Pero en los derechos fundamentales lo que se pretende es ampliar el principio de igualdad referente al otorgamiento de beneficios jurídicos (Ferrajoli, 2009).

Ahora bien, cuando las sociedades persiguen intereses colectivos, procuran garantizarlos a través de su axiomatización como derechos fundamentales. Sin embargo, es posible que, en su etapa inicial, estos derechos sean disfrutados por un grupo limitado de individuos. Ello implica que, aunque nominalmente se les haya calificado como fundamentales, desde la perspectiva formalista-estructuralista no lo son, por no beneficiar igualitariamente a la totalidad de ese conglomerado social.

La utilidad del principio de igualdad es medular en la visión ferrajoliana, porque al ampliar la distribución de dicho beneficio a todos los miembros de determinada comunidad, un bien de pocos se transforma inmediatamente en lo que se podría llamar propiamente un derecho fundamental (Ferrajoli, 2009). Sobre el aspecto de amplitud de cobertura de los derechos, a través del principio de igualdad, cabe resaltar la coincidencia entre la Teoría Formal-estructuralista de los derechos fundamentales y la Teoría Sustancial del Estado que relaciona el Derecho con la política.

El principio de igualdad, como propiedad conceptual de los derechos humanos, puede analizarse en la relación del Derecho con la política, la cual ha 
tenido importantes variaciones a lo largo de la historia. Su mutabilidad se deriva de grandes sucesos, que han sido determinantes para el cambio de la estructura misma de la sociedad, y que han producido nuevos modelos jurídicos y políticos.

Ejemplo de ello es el modelo del Estado de Derecho, resultado de uno de estos cambios relevantes, el cual se caracteriza principalmente por el reconcomiendo de libertades negativas, que funcionan como limitantes del poder estatal. Este es el producto de las revoluciones burguesas en contra del despotismo de los Estados feudales, en donde los súbditos guardan una relación pasiva con el Estado (Touchard, 1970). La pasividad relacional implica que todo asociado es un objeto sin derechos al servicio del señor feudal.

La superación de esta fase de la humanidad es posible por el ascenso de la burguesía al poder, la cual es determinante para la aplicabilidad de las teorías contractualistas de Hobbes, Locke y Rousseau (Touchard, 1970). Sin embargo, la Revolución Francesa, y su Declaración de los Derechos del Hombre, forja nuevos puntos de análisis en la relación del Estado con sus asociados, de tal manera que empiezan a desarrollarse teorías naturalistas del Derecho, cuyo punto de partida es el Derecho Negativo.

Kant, es uno de los máximos representantes en el desarrollo del status negativo del sujeto respecto al Estado. En La metafísica de las costumbres, el autor sostiene que el derecho puede verse desde dos perspectivas: una es la obligación y otra es la coacción (Kant, 2005). La primera se refiere a que el derecho es el conjunto de condiciones bajo las cuales el arbitrio de sujetos puede conciliarse, donde no interesa el deseo sino la manifestación del mismo, y el ejercicio individual e innato del sujeto a la libertad (Kant, 2005). Cabe anotar que la libertad como derecho solo es interesante si se dinamiza por medio de arbitrios, respecto a los cuales importa la forma en la que se relacionan, y no la razón de ello.

En cuanto al derecho como coacción, surge algo interesante de la relación "Estado-individuo", ya que el poder coactivo del Estado, que se ejerce a través del derecho punitivo, solo es legítimo si procura fomentar el principio universal de la libertad (Kant, 2005). El término universal, empleado por Kant, alude a la máxima extensión de una proposición, al igual que lo formula Ferrajoli en su teoría formalista. Esto implica un Estado ideal, donde "todos" pueden operar su libertad, sin penetrar arbitrariamente en la libertad del otro. Pero dicha pretensión, en muchas ocasiones, no es satisfecha, por lo que el Estado debe intervenir 
exclusivamente para coaccionar al sujeto que no está armonizando su arbitrio con el de los demás asociados (Kant, 2005).

A pesar de todo, en este modelo existe una limitación a la facultad de intervención coactiva del Estado en la mayoría de los asuntos privados de los sujetos, toda vez que se entiende que estos asuntos son un desarrollo de la libertad. Dicha facultad solo es legítima si procura la armonización de una libertad "universal", afectada por el arbitrio desmedido del individuo egoísta (Kant, 2005).

La ausencia de intervención estatal en la ejecución de libertades individuales es problemática, debido a que una de las características negativas de este modelo de Estado es que son muy pocas las personas que gozan de la totalidad de sus derechos. Esto conlleva a la necesidad de ampliar el margen de adjudicación de los mismos, para poder cumplir con el valor fundamental de la igualdad, el cual es transgredido, de diversas maneras, en el modelo liberal de derecho.

Al no poder satisfacer las condiciones mínimas de supervivencia de la mayoría de los sujetos, estos no pueden acceder a los derechos de primera generación, sino que deben concentrar sus esfuerzos para garantizar sus necesidades básicas. Así mismo, aunque en el tránsito del Estado de derecho al Estado democrático se establecen pautas para que el sujeto pueda hacer exigencias al Estado, los derechos políticos son exclusivamente de las oligarquías (Peces-Barba, 1995).

Estas formas transgresoras de la igualdad son superadas por el modelo de Estado Democrático, donde se amplía la participación política a través del voto popular, que puede ser ejercido por cualquier ciudadano (Prieto, 2016). El poder de la mayoría, representado en el órgano legislativo, permite modificaciones favorables para el valor de la igualdad. Lastimosamente, el debate sobre la posibilidad de modificar los derechos propios del status negativo revela un nuevo tipo de dictadura, la de las mayorías, la cual sostiene que es posible modificar los derechos individuales si así lo decide el pueblo.

Los actos inhumanos producto de la Segunda Guerra Mundial son determinantes en la superación de esta concepción problemática, puesto que implican la elevación del estatus del derecho y de la democracia sobre el poder estatal. Este último no puede alterar cuestiones de los dos primeros, de tal manera que estos se convierten en los límites externos del Estado (Peces-Barba, 1995).

Por último, el Estado Constitucional de Derecho representa la relación más avanzada entre el Derecho y la política. La construcción valorativa de derechos 
fundamentales, de segunda y tercera generación, logra responder a teorías políticas participativas, como la teoría de la justicia de Rawls y el iusmoralismo de Dworkin, donde la democracia juega un papel importante. En este tipo de Estados, la relación derecho-política emerge con el fundamento de validez de las normas jurídicas, las cuales están supeditadas a un control de constitucionalidad que puede realizarse de manera previa a la promulgación, o posteriormente a la misma, a través de una acción de inconstitucionalidad.

La relación no solo está presente en la dimensión legislativa, sino también en la judicial, al establecer un tribunal constitucional encargado de la protección de la misma Constitución (Peces-Barba, 1995), fallando casos particulares y generando jurisprudencia cuyo contenido interpretativo funge como precedente. Así mismo, se atribuyen obligaciones para todos los jueces ordinarios, destinadas a garantizar los derechos fundamentales consagrados en la Carta Magna.

Solo los modelos de Estado constitucional contemporáneos permiten el desarrollo adecuado de la teoría estructural y tríadica. En ellos, las desigualdades de adjudicación solo son posibles en la medida en que se extienden a las dos limitaciones de los derechos fundamentales, a saber, la referente a la ciudadanía de las personas y la que restringe la capacidad de obrar de los sujetos (Ferrajoli, 2009). Las demás limitaciones, propias de modelos de Estado pre-constitucionalizados, han sido eliminadas conforme la evolución de la relación entre Derecho y política.

Precisamente, en este proceso de reducción de límites, se vuelve evidente la influencia de la moral convencional, porque permite romper los paradigmas de comportamiento social enfocados en la capacidad de la persona (Ferrajoli, 2009). En ese orden de ideas, es claro que el avance del Derecho no radica en crear nuevas codificaciones ni instituciones jurídicas, sino en la posibilidad de universalizar los derechos a todos los miembros de un conglomerado social, tanto en el aspecto jurídico-formal como en el político-jurídico.

$\mathrm{Al}$ igual que la teoría triádica de los derechos humanos como derechos fundamentales, la teoría formalista-estructuralista considera indispensable lograr una distinción entre los derechos fundamentales y los derechos patrimoniales, ya que estos conceptos tienden a confundirse, por ser parte del conjunto de los derechos subjetivos. 
Teniendo en cuenta las distinciones antes mencionadas, es menester analizar otro aspecto importante en la teoría de los derechos humanos como derechos fundamentales, que concierne a la garantía de los mismos. En la teoría de Ferrajoli, la garantía es considerada como un elemento estructural indispensable en la construcción del concepto. De esta manera, algunos juristas y filósofos argumentan que si el derecho no posee garantías no puede calificarse como fundamental, así su adjudicación sea universal (Ferrajoli, 2009). Dichas afirmaciones son eminentemente teóricas, es decir, no tienen una correspondencia fáctica con los sistemas jurídicos existentes. Tal es el caso de las antinomias, que, aunque teóricamente no son posibles, son padecidas en la realidad por los ordenamientos jurídicos.

Al considerar los grandes aportes de la teoría triádica de Peces-Barba y de la teoría formal estructuralista, es posible desarrollar una designación plausible de los derechos humanos como derechos fundamentales, para así estructurar su dimensión semántica. Se puede empezar por afirmar que este tipo de expresiones son derivaciones racionales y deliberativas del principio supremo de la dignidad humana, debidamente axiomatizadas como derechos fundamentales. Estos son adjudicados igualitariamente a todos los miembros del conglomerado social por el poder estatal, el cual debe garantizar su satisfacción material a través de todos los medios políticos y jurídicos.

Esta aproximación semántica, primero, satisface el criterio de fundamentalidad moral, al ser el producto racional y deliberativo de la dignidad humana. De igual manera, cumple con el factor de positivización, que es necesario para la materialización de la moral convencional y para que no sea una simple crítica moral a-jurídica. Por otra parte, refleja la importancia del poder estatal como agente transformador de expectativas justificadas en el derecho vigente. También tiene en cuenta el principio de adjudicación universal, propio de la Teoría Formalistaestructuralista. Finalmente, además de satisfacer la exigencia del elemento "realidad", propio de la teoría triádica, genera el deber de que esto ocurra materialmente, logrando la eficacia que requiere lingüísticamente esta expresión.

\section{La sintáctica de los derechos humanos como derechos fundamentales}

La formalización lógico-simbólica del lenguaje de los derechos humanos como derechos fundamentales requiere la distinción de dos tipos de reglas sintácticas, 
que son las de formación y las de transformación. Las primeras forman las tesis primitivas e indemostrables, como los postulados y las definiciones, y las segundas forman los llamados teoremas, que requieren de demostración a través de las reglas de transformación (Ferrajoli, 2011). El vocabulario del metalenguaje lógico que mejor describe las relaciones sintácticas de estas expresiones es el desarrollado por Ferrajoli en Principio iuris, el cual posee los siguientes signos descriptivos, lógicos y auxiliares.

Los signos descriptivos se dividen, a su vez, en subjetivos y predicativos. Los primeros se emplean para significar agentes o sujetos, simbolizados con letras minúsculas, marcadas numéricamente, para distinguirlos entre sí, como "x0, y1, z2, a3", etc. Además, dentro de esta misma simbología, se adopta el signo “ $\perp ”$, que refiere a la omisión de una acción específica (Ferrajoli, 2011). De ese modo, se puede entender a $x$ como la acción subjetiva positiva materializada por un sujeto, y a $\perp_{\mathrm{x}}$ como la omisión de una acción específica.

Los segundos, los signos predicativos, aluden a las propiedades y relaciones que presentan los agentes, las cuales pueden ser primitivas (dieciséis) o definitorias (doscientas setenta y cuatro) (Ferrajoli, 2011). A continuación, se refieren algunos de los símbolos creados por Ferrajoli para formalizar los signos predicativos que se usan en la sintaxis de los derechos humanos como derechos fundamentales:

- Predicativos primitivos: permitido (PER), comportamiento (COM), modalidad (MOD), expectativa (ASP), interés (INT), estatus (STA), sujeto (SOG), objeto (OGG), significado [prescriptivo] (SIG), regla (REG), conjunto (INS), causa (CAU), constituye (COS), constatación (ACC), fuerza (FZA) y democrático (DEM) (Ferrajoli, 2011).

- Predicativos definidos: facultativo (FCO), prohibido (VIE), obligatorio (OBB), vinculado (VIN), permiso positivo (PEM), permiso negativo (PEM1), facultad (FAC), obligación (OBL), prohibición (DIV), imperativo (IMR), actuación (ATZ), ejercicio (ESE), obediencia (OTT), desobediencia (INO), satisfacción (SOD), violación (VIO), efectividad (ETT), inefectividad (INE), autor (AUT), titular (TIT), imputado (IMP), relación deóntica (RAD), garantía (GAR), garantía positiva (GPO), garantía negativa (GNE), colectivo (COL), ventaja (VAN), desventaja (SVA), cosa (COA), uso (USO), signo (SEG), precepto (PRE), prescripción (PRS), 
precepto deóntico (PDE), precepto constitutivo (PCO), regla tética (RTE), regla hipotética (RIP), regla deóntica (RDE), regla constitutiva (RCO), observancia (OSS), inobservancia (OSS), efectividad de grado (ETT), inefectividad de grado (INE), efecto (EFF), acto (ATT), eficacia (EFC), derecho potestad (DIP), grado subordinado (GSU), relación de grado (RGR), situación (SIT), actuabilidad (ATB), situación activa (SIA), situación pasiva (SIP), prueba (PRV), interpretación (INP), estatus jurídico (STG), personalidad (PTA), persona (PES), sujeto jurídico (SGG), persona natural (PNA), persona artificial (PAR), capacidad de obrar (CPA), capacidad jurídica (CPG), capaz de obrar (CAA), capaz jurídicamente (CAG), relación jurídica (RAG), representación (RAP), representante (RNT), representado (RTO), órgano (ORG), pueblo (POP), ciudadano (CIT), ciudadanía (CTZ), bien (BEN), bien material (BMA), bien inmaterial (BIM), norma (NOR), fuente (FON), norma tética (NTE), norma hipotética (NIP), norma deóntica (NDE), norma constitutiva (NCO), norma adscriptiva (NAS), norma atributiva (NAT), norma imperativa (NIM), norma institutiva (NIS), instituto (IST), ordenamiento (ORD), norma de reconocimiento (NRI), razón social (RAS), institución (ISZ), acto institutivo (AIS), forma (FOR), acto formal (AFO), acto informal (AIN), ilícito (ILL), cumplimiento (ADE), incumplimiento (INA), acto preceptivo (APR), acto instrumental (AST), decisión (DEC), acto constitutivo (ACO), norma formal (NFO), norma sustantiva (NSO), norma sobre la producción (NPR), conformidad (COF), coherencia (COE), vigencia (VIG), validez (VAL), validez formal (VAF), validez sustancial (VAS), invalidez (INV), invalidez formal (IVF), invalidez sustancial (IVS), vicio (VIZ), vicio de forma (VIF), vicio de sustancia (VIS), legitimidad (LGT), ilegitimidad (ILG), legitimidad formal (LGF), ilegitimidad formal (ILF), derecho fundamental (DFO) y derecho subjetivo (DIR) (Ferrajoli, 2011).

Por otra parte, los signos lógicos, empleados en la síntesis de los derechos fundamentales, se dividen entre los de enlace y los operadores. Los primeros son la negación “ $\neg$ ”, la conjunción “\&”, la disyunción "V”, la condición “ $\rightarrow$ ” y la bicondición $(\leftrightarrow)$ (Supess \& Hill, 1988). Los segundos son símbolos de constantes y se dividen en: cuantificadores, que son "para todo x vale (x)", "existe al menos 
un $\mathrm{x}$ que (马x)" y “existe un número n de x que (马 " $\mathrm{X}$ )"; y operadores modales, que son los de necesidad (1) y posibilidad (M) (Ferrajoli, 2011).

\section{Las reglas de formación}

Ahora bien, teniendo en cuenta todos los signos antes descritos, se posibilita su relación a través de los dos preceptos enunciados al principio de este apartado, que son las reglas de formación y las reglas de transformación.

En cuanto a las reglas de formación, estas aluden a las combinaciones que se pueden hacer con los signos de la teoría para elaborar "expresiones bien formadas". Básicamente por medio de ellas se construyen cuatro tipos de enunciados: los simples, los compuestos, los generales y los modales (Ferrajoli, 2011).

Los enunciados simples están "formados por un functor predicativo seguido de un cierto número de variables subjetivas. Si el functor afecta a una sola variable es monádico, como se ve en la forma simbólica de $x$ es obligatorio OBBx, en cambio, si lo hace con más de uno es poliádico, como la forma simbólica de " $y$ es obligación de x” OBByx" (Ferrajoli, 2011, p. 599).

Los enunciados compuestos son los que resultan de la relación entre los enunciados simples, a través de los términos de enlace. Téngase en cuenta que los conectores lógicos también son functores extensionales de verdad, esto lleva a que la veracidad del producto final dependa de la de las partes que la conforman (Kalinowski, 1973). Por ejemplo, "VIE $\mathrm{x} \rightarrow \mathrm{x} \rightarrow(\mathrm{PER} \perp \mathrm{x} \& \neg \mathrm{PERx})$, si $x$ está prohibido, entonces está permitido omitir $x$ y no está permitido $x$ " (Ferrajoli, 2011, p. 31).

Los enunciados generales son producto de la aplicación de un cuantificador a un enunciado simple o a uno compuesto. Esto los cierra, debido a que respecto a ellos se puede predicar una verdad empírica, lo cual los diferencia de los que se consideran abiertos, puesto que carecen de cuantificador. Por ejemplo, “(x) ( $\neg$ VIEx V $\neg$ OBBx)", expresa: para todo $x$, o $x$ no está prohibido, o $x$ no es obligatorio.

Por último, los enunciados modales surgen como consecuencia de la aplicación, a los otros tipos de enunciados, de uno o más operadores modales. Por ejemplo, “(y) (FACy $\leftrightarrow$ M (马x) FACyx), expresa: para todo y vale que, y es una 
facultad, si y solo si, existe algún x para el cual y es una facultad" (Ferrajoli, 2011, p. 35).

\section{Las reglas de transformación}

Las reglas de transformación son las que ayudan a relacionar las expresiones producidas a través de las reglas de formación. Por medio de ellas se extraen teoremas de los axiomas que fungen como premisas de derivación. Este tipo de reglas surgen del cálculo proposicional o de inferencia y expresan la misma proposición, alterando la sintaxis del enunciado. Entre ellas se encuentran la conmutación, la doble negación, la simplificación disyuntiva, la simplificación conjuntiva, las leyes de Morgan, etc. (Supess \& Hill, 1988).

En cambio, las reglas de inferencia lógica requieren dos o más premisas que permitan su relación. Entre ellas están: ponendo ponens, tollendo tollens, tollendo ponens, silogismo hipotético, silogismo disyuntivo, implicación destructiva, ley de la bicondición, etc. (Supess \& Hill, 1988). Vale aclarar que la aplicabilidad de las reglas antes referenciadas depende de la formación de un caso concreto para su respectiva aplicación. Sin embargo, la presente investigación no está enfocada en develar el funcionamiento del sistema lógico de los derechos humanos para la solución de casos concretos, sino que pretende exponer la formulación sintáctica de dichas expresiones como derechos fundamentales. Por ello, la derivación de teoremas mediante las reglas de inferencia en la solución de casos será tema de otra investigación.

De acuerdo a la simbología de Ferrajoli, los derechos humanos poseen la siguiente sintaxis: “(y)(DUMy $\leftrightarrow($ DIRy \& (z)(TITzy \& PNAz)))”. Esta se lee, en términos lógicos, de la siguiente manera: "para todo $y$, vale que $y$ es un derecho humano, si y solo si $y$ es un derecho subjetivo, y para todo $z$ vale que $z$ es titular de $y$, y que $z$ es una persona natural" (Ferrajoli, 2011, p. 600).

Por su lado, la teoría formal-estructuralista, al considerar los derechos fundamentales como una subespecie de los derechos subjetivos, cambia su forma sintáctica: (y)(DFOy ↔ ((DIRy \& ((z) (TITzy \& PNAz) V (z)(TITzy \& CITz))) V (DIPy \& ((z) (TITzy \& CAAz) V (z) (TITzy \& CITz \& CAAz)))). De esta manera, la descripción gramatical indica: "para todo $y$ vale que $y$ es un derecho fundamental, si y solo si $y$ es un derecho subjetivo, siendo $z$ una persona natural 
y titular del mismo, o siendo $z$ un ciudadano, o siendo $z$ un capaz de obrar, o siendo $z$ titular de $y$, o siendo ciudadano con capacidad de obrar" (Ferrajoli, 2011, p. 605).

Como se puede observar, la sintaxis de los derechos fundamentales contiene la formulación básica de los derechos humanos, después del término de enlace bicondicional. Sin embargo, estos derechos se diferencian en tanto los fundamentales abarcan más posibilidades disyuntivas que los humanos, como los derechos de ciudadanía y los que necesitan de capacidad legal para ser ejercidos.

\section{La pragmática de los derechos humanos como derechos fundamentales}

La operatividad de la dimensión pragmática de los derechos humanos responde a los dos lados de la comunicación básica, es decir, a la posición del emisor y a la del receptor. Desde la primera, resulta llamativo que el origen de los derechos humanos sea de corte occidental y que responda a las necesidades históricas de la civilización europea. Ejemplo de ello, es que el término dignidad humana, del que derivan la gran mayoría de los derechos humanos, es producto de la interpretación teológica sincretista del génesis bíblico, que se enfoca en la solución de los problemas sociales y políticos de la Europa del siglo XIV (Pico Della Mirandola, 2004).

El expansionismo bélico, presente en los procesos de colonización y evangelización del nuevo mundo, no solo permite la explotación económica del territorio americano, sino que también sirve para la imposición de la cultura europea y de su tradición jurídica (Agudelo et al., 2017). Este fenómeno es denominado por los antropólogos como aculturación, la cual consiste en un ataque a nivel semiótico, con el propósito de que los sujetos afectados olviden sus raíces lingüísticas y teológicas, facilitando la imposición de las creencias y lenguajes provenientes del viejo continente (Aguirre, 1957).

En el contexto sociohistórico colombiano se ve claramente la distorsión semántica de algunas palabras de origen chibcha, como "guiza", "guaricha" y "guache", que etimológica y respectivamente significan: "esposa", "princesa" y "príncipe". Sin embargo, los invasores trasformaron su significación a: "mujer de pocos modales, prostituta y hombre grosero" 
Posteriormente, el pensamiento moderno, caracterizado por su exigencia de homogeneidad y uniformidad, consolida el punto de vista occidental en la mayoría de naciones del mundo. De ello son ejemplo manifestaciones como la Declaración de los Derechos del Hombre y del Ciudadano y la Proclamación de los Derechos Humanos. Estas conllevan una pretensión de universalidad, que implica que dichas expresiones jurídicas sean para todas las personas, sin distinción de raza, credo, nacionalidad o género.

Ahora bien, en el análisis del otro lado de la dimensión pragmática de la relación comunicativa, la del intérprete como receptor de las expresiones jurídicas, subyace un problema. Este tiene que ver con la propiedad de adjudicación "universal" de los derechos humanos a nivel operativo, puesto que, en realidad, estos siguen siendo un beneficio de los miembros de la comunidad europea. Los profesores colombianos Óscar Agudelo y Jorge León (2017) denominan este fenómeno como la "hipocresía de los derechos humanos", que se presenta

cuando los países a los que les fue implantada dicha homogeneidad o identidad jurídica reclaman la efectividad de los derechos humanos [y] los países fundadores cierran sus puertas y determinan que estos derechos son prerrogativas para aquellos que gozan de ciudadanía, es decir, demarcan la existencia de los derechos humanos solo entre Naciones que gozan de una misma identidad jurídica, política y social (Agudelo et al., 2017, p. 10).

La hipocresía es evidente en las políticas migratorias de la Unión Europea, que buscan reforzar las fronteras de sus Estados periféricos, con el fin de que los individuos que no hacen parte de esta comunidad no puedan ejercer el proceso de migración (Agudelo et al., 2017). La forma jurídica para la limitación de estos derechos "universales" es el factor ciudadanía, que hace parte de la transformación de estas expresiones en derechos fundamentales. De ese modo, se logra establecer la llamada fórmula de exclusión. Por lo anterior,

es posible concluir que la fórmula hipócrita de los derechos humanos subyace, de facto, en la fórmula de exclusión que originan los Estados mismos. Esta fórmula de exclusión parte de dos términos contrarios, como en la tercera persona del verbo plural, el código binario nosotros-ellos, equivalente al código binario clásico del Derecho Internacional nacional-extranjero (Agudelo et al., 2017, p. 14).

Así, es necesario separar la noción de ciudadanía de los derechos fundamentales como la forma de los derechos humanos, para lograr satisfacer el criterio 
de universalidad, que es parte esencial de su estructura lingüística. Sin embargo, lastimosamente, dicha labor no depende de los estudios que puedan desarrollar los académicos, sino que está en manos de los que ostentan el poder político de las grandes potencias nacionales del mundo. Esto lleva a que la adjudicación y la satisfacción efectiva de estas expresiones dependan, en gran medida, de la validez de las posiciones morales de estos sujetos.

\section{Conclusiones}

Se puede concluir que el desarrollo semiótico de los derechos humanos es posible en la medida en que estos adoptan la forma de derechos fundamentales, toda vez que los modelos ofrecidos por las corrientes tradicionales del Derecho no logran abarcar toda su complejidad lingüística. Sin embargo, no todos los modelos teóricos de los derechos fundamentales ofrecen los elementos necesarios para su adecuada construcción semántica, ya que su significación debe incorporar cuatro elementos básicos, que son: la fundamentación, que es donde se encuentra la justificación moral del derecho; la positivización, donde la convención moral es transformada por el poder estatal en un derecho positivo exigible; la eficacia relacionada al componente realidad de los derechos y su ejercicio material empírico; y la universalidad, entendida como la capacidad de adjudicación a todos las personas.

Teniendo en cuenta las propiedades conceptuales de los derechos humanos como derechos fundamentales, el paso a seguir desde un ámbito semiótico es su formalización sintáctica, de modo que se pueda elucidar el funcionamiento lógico de la expresión. Para lograr dicho cometido es necesaria la simbología propuesta por Luigi Ferrajoli (2011) en su obra Principio iuris, debido a que este autor abarca los avances investigativos lógicos desarrollados en los siglos Xx y XxI, los cuales revelan las limitaciones de las lógicas tradicionales.

Así mismo, de la mano de Ferrajoli se puede abordar parte de la lógica deóntica, que es la lógica de las proposiciones prescriptivas, punto que es sumamente importante, en el sentido de que este tipo de proposiciones son las que expresan el lenguaje normativo del derecho. De la misma manera, simbólicamente elucida la identidad lógica en la sintaxis de los derechos humanos con los derechos fundamentales. 
Sin embargo, subyace un problema en esta última formalización, el cual consiste en la inclusión de la sintaxis de la ciudadanía y de la capacidad de obrar. El rechazo en la implicación de estos dos elementos, en la forma lógica de los derechos fundamentales, se revela en su dimensión pragmática, ya que operativamente muestra cómo estas dos nociones limitan el principio de universalidad, que es medular en su lingüística.

\section{Referencias}

Agudelo, O. et al. (2017). Análisis y aplicación de los derechos humanos en el contexto de la corte interamericana. Bogotá: Universidad Católica de Colombia.

Aguirre, G. (1957). El proceso de aculturación. México D.F: Dirección general de publicaciones de la UNAM.

Campos, G. (2006). Racionalidad y argumentación jurídica legislativa. México D.F: Centro de Estudios de Derecho e Investigaciones Parlamentarias.

Courtis, C. (2006). Observar la ley. Madrid: Trotta.

Dworkin, R. (2007). Los derechos en serio. Barcelona: Ariel.

Dworkin, R. (2014). Justicia para erizos. México DF: Fondo de Cultura Económica.

Echave, D., Urquijo, M., \& Guibourg, R. (2008). Lógica, proposición y norma. Buenos Aires: Astrea.

Ferrajoli, L. (2009). Los fundamentos de los derechos fundamentales. Madrid: Trotta.

Ferrajoli, L. (2011). Principio Iuris. Teoría del derecho y de la democracia. Madrid: Trotta.

Gianella de Salama, A. (1986). Lógica simbólica y elementos de metodología de la ciencia. Buenos Aires: El Ateneo.

Guastini, R. (2011). Distinguiendo. Barcelona: Gedisa.

Habermas, J. (2001). Facticidad y validez. Madrid: Trotta.

Kalinowski, G. (1973). Introducción a la lógica jurídica. Buenos Aires: EUDEBA.

Kalinowski, G. (1995). Acerca de la semántica del leguaje del derecho. Revista de la Universidad de Mendoza, (14), 119-133.

Kalinowski, G., \& Landowski, E. (1990). Semiótica jurídica. Cuadernos del instituto de investigaciones jurídicas, (14), 320-326.

Kant, I. (2002). La metafisica de las costumbres. Madrid: Tecnos.

Kant, I. (2005). La metafisica de las costumbres. Madrid: Tecnos. 
Kelsen, H. (1986). Teoría pura del derecho. México D.F.: Universidad Nacional Autónoma de México.

Mardones, J. \& Ursúa, N. (2012). Filosofia de las ciencias humanas y sociales. Barcelona: Anthropos.

Morales, L. (2015). Violencia cultural, colonialismo y reetnización; el sentido de las prácticas en salud desde el punto de vista indígena. Revista de la facultad de medicina, 63(4), 699-706.

Nino, C. (2001). Introducción al análisis del derecho. Barcelona: Ariel.

Peces-Barba, G. (1995). Curso de derechos fundamentales teoría general. Madrid: Editorial de la Universidad Carlos III de Madrid.

Pico Della Mirandola, G. (2004). Discurso sobre la dignidad humana. México D.F.: Universidad Nacional Autónoma de México.

Prieto, M. (2015). La moralidad como base para el proceso de axiomatización. Novum Jus, 9(1), 29-49.

Prieto, M. (2016). ¿Es posible la construcción de metarreglas para la regulación del control popular de interpretación constitucional? Soft Power, 219-228.

Rawls, J. (1993). Teoría de la justicia. México D.F.: Fondo de Cultura Económica.

Supess, P. \& Hill, S. (1988). Introducción a la lógica matemática. Bogotá: Reverté.

Touchard, J. (1970). Historia de las ideas políticas. Madrid: Tecnos.

Vergara, R. (2000). El bloque de constitucionalidad. Estudios de derecho, 13-36.

Von Wright, G. (1951). Deontic Logic. Mind, 60(237), 1-15.

Von Wright, G. (1979). Norma y acción. Madrid: Tecnos.

Von Wright, G. (2001). Normas, verdad y lógica. México D.F.: Fontamara. 